\title{
Synthesis and characterization of nanocomposites based on polyaniline-gold/graphene nanosheets
}

\author{
Deepshikha Saini · T. Basu
}

Received: 17 October 2011/Accepted: 11 January 2012/Published online: 2 February 2012

(c) The Author(s) 2012. This article is published with open access at Springerlink.com

\begin{abstract}
Polymer nanocomposites (NSPANI/AuNP/GR) based on nanostructured polyaniline, gold nanoparticles (AuNP) and graphene nanosheets (GR) have been synthesized using in situ polymerization. A series of nanocomposites have been synthesized by varying the concentration of GR and chloroauric acid to optimize the formulation with respect to the electrochemical activities. Out of these series of NSPANI/AuNP/GR nanocomposites, it has been found that only one particular nanocomposite has the best electrochemical properties, as analyzed by cyclic voltammetry (CV) and differential pulse voltammetry and conductivity. The best nanocomposite has been characterized by Fourier transform infrared Raman spectroscopy, UV-vis spectroscopy, X-ray diffraction studies, transmission electron microscopy, scanning electron microscopy and atomic force microscopy. The $\mathrm{CV}$ of the best nanocomposites show the well-defined reversible redox peaks characteristic of polyaniline, confirming that the polymer maintains its electro activity in the nanocomposites. Another nanocomposite has been prepared with identical composition (as found with the best nanocomposite) by mixing of presynthesized nanostructured polyaniline with chloroauric acid and graphene dispersion in order to predict the mechanism of in situ polymerization. It is inferred that the nanocomposite prepared by blending technique loses its property within $48 \mathrm{~h}$ indicating phase separation whereas the nanocomposite prepared by in situ technique is highly stable.
\end{abstract}

D. Saini $(\bowtie) \cdot$ T. Basu

Amity Institute of Biotechnology,

Amity University Uttar Pradesh, Noida 201303, India

e-mail: dshikha@amity.edu
Keywords Polyaniline nanocomposite . Graphene nanosheet · Gold nanoparticles · Electrochemical properties

\section{Introduction}

In recent years, conductive polymers synthesized in the form of nanostructures are of particular interest since their unique morphology with high specific surface area usually results in very exclusive advantages such as improved dispersion ( $\mathrm{Li}$ et al. 2007) in organic and inorganic solvents, enhanced electronic conductivity (Banerjee and Mandal 1995; Thanpitcha et al. 2008) and response to sensor applications (Virji et al. 2004; Huang et al. 2004). Their synthesis and chemical modification offer unlimited possibilities unlike inorganic metals and semiconductors, which is an advantage with these polymers. It is possible to reduce the structural disorder in doped conducting polymers by choosing optimum parameters during synthesis. It is worthwhile to mention that the nanostructured intrinsically conducting polymers (NSICP) offer reduced structural disorder which consequently helps in increasing the electronic conductivity of the polymers (Bianchi et al. 1999). The nanostructured conducting polyaniline (NSPANI) is unique among the family of conducting polymers because of its ease of synthesis, environmental stability, tunable electronic conductivity, versatile electrochemical switching behavior (Xia et al. 2010), reversible doping/dedoping chemistry(Huang et al. 1986; MacDiarmid 1997; MacDiarmid et al. 1985) excellent mechanical strength, and suitability for making composites with different types of binders, which make it one of the most suitable components in the fabrication of macromolecular electronic devices such as opto and microelectronics, photonics (Holdcroft 
2008), sensors in chemical (Virji et al. 2004), electrochemical (Janata and Josowicz 2003; Wang and Chan 2004) and biological applications (Liu et al. 2005). Nanostructured polyaniline has been mainly obtained with the aid of template-guided polymerization within channels of microporous zeolites, electrodes, porous membranes or via chemical routes in the presence of self-organized supramolecules or stabilizers and non-templated routes (Nandi et al. 2007).

Graphene, a two-dimensional sheet of $\mathrm{sp}^{2}$ conjugated atomic carbon, has stimulated intense research interest because of its unique band structure, massless fermions, and ultrahigh carrier mobility (Geim 2009; Tang et al. 2010). These unique properties hold great promise for potential applications in many technological aspects such as nanoelectronics, sensors, nanocomposites, batteries, supercapacitors and hydrogen storage (Li et al. 2008). The high specific surface area of $2,630 \mathrm{~m}^{2} / \mathrm{g}$ enables it to afford an ultrahigh loading capacity for biomolecules and drugs (Tang et al. 2010; Liu et al. 2008). Recently, graphene has been successfully used in many bioassay applications (Tang et al. 2010; Lu et al. 2010; Dong et al. 2010). Due to the excellent properties of graphene and the advantages of polyaniline, it is most likely chosen to be the conductive polymer backbone for graphene-polymer composites. An important aspect of such graphene-based composite materials is to maintain the graphene sheets as thin as possible and to disperse them homogeneously in the matrix, which is necessary for improving its electrochemical properties. Both electrochemical and chemical methods have been used to synthesize the composite in reported literatures (Wang et al. 2009a, 2010; Murugan et al. 2009). Very recently, Goswami et al. (2011) have focused on the synthesis of composites of PANI- $\beta$-camphor sulfonic acid ( $\beta$-CSA) nanofibers with graphene oxide (GO) and Graphene (GR) and have investigated the cold cathode field emission performance of the same. Bai et al. (2009) employed sulfonated polyaniline and Zhou et al. (2010) developed a synthesis mediated by polymerized ionic liquid for the preparation of stable aqueous dispersions of polyaniline/graphene materials. Some recent studies have already discussed about the structural, optical, electrical and thermal properties of graphene-polyaniline composites and concluded that these composites can be utilized for numerous applications in nanoelectronics, rechargeable batteries, electromagnetic interference (EMI) shielding and many more (Zhang et al. 2010; Wu et al. 2010; Bourdo et al. 2008).

Also, several studies have been performed on the electrochemical properties of metal-doped graphene (Hongkun and Chao 2011; Zhang et al. 2011; Shen et al. 2010) as well as in the area of metal-doped graphene (GR)/conducting polymer (CP) composites (Stoller et al. 2008; Wang et al. $2009 b$ ). The metal nanoparticles deposited onto the graphene serve as an efficient catalyst to improve electrochemical performance of the GR/CP and that they resulted in the increase of the charge transfer between GR and $\mathrm{CP}$ by bridge effect (Kim et al. 2010). However, there has been limited work in the area of metal-doped NSCP/graphene composites.

Recently, conducting polymer nanocomposites have attracted much attention for their ability to enhance electrical and mechanical properties by synergistic effects through the interaction of the two components. For example, graphene-conducting polymer composites have also become attractive as electrode materials due to their combination effect as low-dimensional organic conductors and a high surface area and excellent conductivity of graphenes. Also, several studies have been performed on the electrochemical properties of metal-doped graphene, whereas there has been limited work in the area of metal/ graphene/conducting polymer composites (Stoller et al. 2008; Wang et al. 2009b).

Therefore in the present study, polymer nanocomposites (NSPANI/AuNP/GR) based on nanostructured polyaniline (NSPANI), gold nanoparticles (AuNP) and graphene nanosheets (GR) have been synthesized using in situ polymerization. A series of nanocomposites have been synthesized by varying the concentration of graphene and chloroauric acid to optimize the formulation with respect to the electrochemical activities, conductivity and stable film forming property. Another NSPANI nanocomposite with identical composition was prepared by mixing of pre-synthesized nanostructured polyaniline with chloroauric acid and graphene dispersion in order to predict the mechanism of in situ formation of nanocomposite and to compare the electrochemical properties of both the nanocomposites.

\section{Experimental}

\section{Materials}

Few layered graphene (Quantum materials corporation, Bangalore), Aniline (Sigma-Aldrich), sodium dodecyl sulphate (SDS) (Qualigen), ammonium persulfate $\left(\mathrm{NH}_{4}\right)_{2} \mathrm{~S}_{2} \mathrm{O}_{8}$ (E-Merck), hydrochloric acid (Qualigen), Chloroauric acid $\mathrm{HClO}_{4}$ (Sigma-Aldrich) were used in the present experiment. Deionized water from a Millipore-MilliQ was used in all cases to prepare aqueous solutions. Monomer was double distilled before polymerization.

Polymerization procedure

\section{In situ polymerization}

In a typical synthesis, graphene was first dissolved into a dilute aqueous solution of sodium dodecyl sulphate (SDS) 


$$
\begin{aligned}
& \text { I- } \mathrm{NH}_{2} \mathrm{H}^{+} \longrightarrow \text { - } \\
& 3\langle\text { - } \\
& \mathrm{n}\left\langle-1 .=\stackrel{+}{\mathrm{N}_{2}} \stackrel{\left(\mathrm{NH}_{2}\right)_{2} \mathrm{~S}_{2} \mathrm{O}_{8}}{\longrightarrow}\right. \text { Polyaniline }
\end{aligned}
$$

Scheme1 The proposed mechanism for the reaction of aniline with $\mathrm{HAuCl}_{4}$

$(0.02 \mathrm{M})$. The aniline solution in the dopant $(0.02 \mathrm{M})$ was added to an aqueous solution of SDA under stirring condition. The mixture was then placed in the low temperature bath, so that the temperature was maintained at $0-5^{\circ} \mathrm{C}$. $70 \mu \mathrm{l}$ of aqueous $0.05 \mathrm{M} \mathrm{HAuCl}_{4}$ was added into aqueous dispersion. An aqueous solution of the oxidizing agent, $\left(\mathrm{NH}_{4}\right)_{2} \mathrm{~S}_{2} \mathrm{O}_{8}$, in ice-cold water was added to the above mixture. The polymerization was allowed to proceed for 3-4 h with stirring. After that the stirring was stopped and the mixture was kept under static condition for 1-3 days at $277-278^{\circ} \mathrm{K}$ for polymerization to complete. The proposed mechanism for the reaction of aniline with $\mathrm{HAuCl}_{4}$ is shown in Scheme 1. Experimental conditions for the synthesis of samples is given in Table 1.

\section{Blending process}

Pre-synthesized polyaniline nanoparticles (NSPANI) were mixed with graphene and gold. Time for the addition of gold solution was varied by keeping the other two parameters (graphene and NSPANI) constant. The mixture was truncated to the homogeneous nanocomposite of the three materials NSPANI/AuNP/GR after $2 \mathrm{~h}$ of stirring. Four NSPANI/AuNP/GR nanocomposites were prepared by blending process as summarized in Table 2 .

\section{Characterization}

The UV-vis spectrum of the nanocomposites was recorded using a Shimadzu UV-1800 UV-vis spectrophotometer. Morphological imaging was obtained by transmission electron microscope (TEM), using a JEOL JEM-1011 at $80 \mathrm{kV}$ and scanning electron microscope (LEO 440
Model). FT-IR Raman spectra of these samples were recorded using a Varian-FT-IR spectrometer series II. Atomic force microscopy (AFM) was performed by Park Systems XE-70 Atomic Force Microscope in non-contact mode. X-ray analysis was performed using a Rigaku make powder X-ray diffractometer (model RINT 2100) with a $\mathrm{Cu}$ target $(\lambda=1.54059 \AA)$. Cyclic voltammetric study was carried out using Autolab Potentiostat/Galvanostat Model 273A.

\section{Results and discussion}

\section{UV-vis spectroscopy}

Figure 1 shows UV-visible spectra of NSPANI and NSPANI with different compositions of graphene and gold nanoparticles. All the samples show three characteristic absorption bands at 320-380, 400-432 and 791-812 nm wavelengths. The first absorption band is related to $\pi-\pi^{*}$ band transition, second and third absorption bands are due to the formation of polaron and bipolaron, respectively (Stejskal and Kratochvil 1993). As no discrete change has been identified in the absorption maxima of $\pi-\pi^{*}$ band in all the cases, we have focused our study only on polaron absorption band in the visible region because polaron band is more localized. Polaron absorption band for NSPANI appears at $802 \mathrm{~nm}$. Presence of this peak shows that NSPANI is in the emeraldine salt form which is also called the conducting state of polyaniline. A gradual hypsochromic shift of the polaron absorption band in the visible region has been observed for NSPANI/GR indicating that graphene doping took place on the quinoid ring of polyaniline to form conductive NSPANI/GR. In case of NSPANI/AuNP/GR nanocomposite, gradual bathochromic shift is observed as compared to NSPANI/GR. This is due to the fact that gold nanoparticles will act as conductivity bridges between NSPANI and graphene to increase the conductivity of the nanocomposite. At the fixed aniline (0.02 M), SDS (0.02 M) and gold nanoparticles concentration, if we change the concentration of graphene there occurs a hypsochromic shift in the polaron absorption band. This suggests the change in doping characteristics. Insufficient doping of graphene into the polyaniline chains
Table 1 Experimental

\begin{tabular}{|c|c|c|c|c|c|}
\hline Sample no. & Sample name & ANI:graphene & ANI:AuNP & Color & Stability \\
\hline 1 & NSPANI/GR & $100: 1$ & & Dark green & Highly stable \\
\hline 2 & NSPANI/AuNP/GR1 & 100:0.5 & 100:0.4 & Dark green & Highly stable \\
\hline 3 & NSPANI/AuNP/GR & $100: 1$ & 100:0.4 & Dark green & Highly stable \\
\hline 4 & NSPANI/AuNP/GR2 & $100: 2$ & $100: 0.4$ & Dark green & Highly stable \\
\hline 5 & NSPANI/AuNP1/GR & 100:1 & $100: 0.5$ & Dark green & Highly stable \\
\hline
\end{tabular}
conditions for the synthesis of samples 
Table 2 Experimental conditions for the synthesis of samples

\begin{tabular}{lllll}
\hline Sample no. & $\begin{array}{l}\text { Nanostructured polyaniline } \\
(\text { NSPANI })(\mathrm{ml})\end{array}$ & $\begin{array}{l}\text { Graphene } \\
(\mathrm{GR})(\mathrm{mg})\end{array}$ & Gold $\left(\mathrm{HClO}_{4}\right)(\mu \mathrm{l})$ & $\begin{array}{l}\text { Total time for } \\
\text { stirring }(\mathrm{h})\end{array}$ \\
\hline 1 & 10 & 0.186 & 7 Added after 15 min & 2 \\
2 & 10 & 0.186 & 7 Added after 30 min & 2 \\
3 & 10 & 0.186 & 7 Added after 45 min & 2 \\
4 & 10 & 0.186 & 7 Added after $1 \mathrm{~h}$ & 2 \\
\hline
\end{tabular}

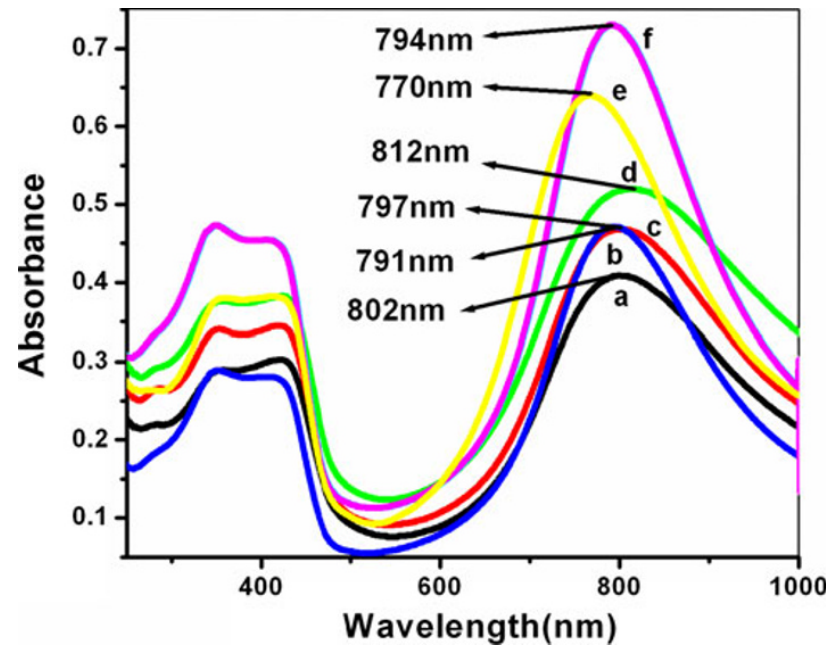

Fig. 1 The UV-vis spectra of $a$ NSPANI, $b$ NSPANI/GR, $c$ NSPANI/AuNP/GR1,$d$ NSPANI/AuNP/GR, $e$ NSPANI/AuNP/GR2 and $f$ NSPANI/AuNP1/GR

occurs when excess or deficient amount of graphene is introduced. Similar result is also obtained if we increase the concentration of gold nanoparticles by keeping the concentration of all other constituents fixed. This shows that the intimate contact between the gold nanoparticles and NSPANI/GR matrix is inadequate. Contact between metal particles and the polymer is crucial in molecular electronic devices because the charge transfer at the contact point plays an important role in its functionality. From these results, the optimum molar ratio of aniline:graphene:gold is 100:1.0:0.37 (Yang et al. 2010).

\section{Cyclic voltammetry (CV)}

Figure 2 shows the CV curves of NSPANI and NSPANI with different compositions of graphene and gold nanoparticles. Positive currents in the figures are for oxidation and the negative currents are for reduction processes. It can be found that there are a couple of redox peaks in $\mathrm{CV}$ curves of NSPANI and the as-prepared composites, attributed to the redox transition of polyaniline between a semiconducting state (leucoemeraldine form) and a conducting sate (polaronic emeraldine form) (Wang et al. 2006), which results in the redox capacitance. The differences between the oxidation and reduction peaks, $\Delta \mathrm{EO}, R$,

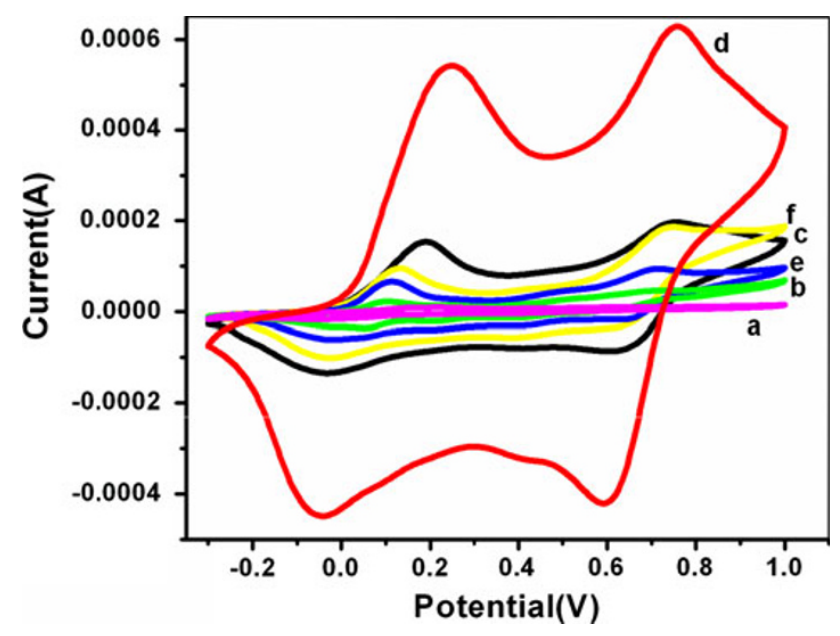

Fig. 2 Cyclic voltammograms of $a$ NSPANI, $b$ NSPANI/GR, $c$ NSPANI/AuNP/GR1, $d$ NSPANI/AuNP/GR, $e$ NSPANI/AuNP/ GR2 and $f$ NSPANI/AuNP1/GR

are taken as estimate of the reversibility of the redox reaction (Wang et al. 2007). Values of 0.15 and $0.19 \mathrm{~V}$ are obtained for the redox reactions of polyaniline with graphene and/or gold incorporation, compared to $0.28 \mathrm{~V}$ for NSPANI, indicating that the redox reactions appear to occur more reversibly after the addition of graphene and gold. In addition, the larger current density response and shifting of peak potential toward the lower potential for NSPANI/AuNP/GR composite electrode indicate higher specific capacitance and high electroactivity than that of NSPANI, NSPANI/GR composites. The dispersion of NSPANI particles on graphene reduces the diffusion and migration length of the electrolyte ions during the fast charge/discharge process and increases the electrochemical utilization of polyaniline. Also, compared to NSPANI/GR, the active surface area of the NSPANI/AuNP/GR is remarkably increased, indicating the enhanced electrochemical properties stemming from the Au nanoparticles deposited onto polyaniline. Therefore, $\mathrm{Au}$ nanoparticles doped onto polyaniline serve as an efficient supporting and catalytic material to enhance the electrochemical properties of NSPANI/AuNP/GR (Kim et al. 2010). The effect of change in the concentration of graphene and gold on the electrocatalytic activity of composites was also studied. It has been found that electrocatalytic activity decreases with 
increase or decrease in the concentration of graphene from one particular concentration. This is perhaps due to the insufficient or excess of graphene present for the binding of polyaniline on the surface of graphene sheets. Increase in gold concentration also leads to decrease in the electrochemical activity of nanocomposite. The active surface area of the NSPANI/AuNP/GR is remarkably decreased with the increase of the AuNP concentration, indicating the decreased electrochemical properties stemming from the gold nanoparticles deposited onto NSPANI/GR matrix (Kim et al. 2010). This is possibly due to the fact that the increase of gold concentration decreases the conductivity of nanocomposite. Thus, the optimal ratio of the aniline:graphene:gold was determined to be 100:1.0:0.37 for electrocatalysis (Hong et al. 2010).

\section{Differential pulse voltammetry (DPV)}

Figure 3 shows the CV curves of NSPANI and NSPANI with different compositions of graphene and gold nanoparticles. DPV experiments have been conducted in the range -0.4 to $1.2 \mathrm{~V}$. NSPANI/AuNP/GR has shown remarkable enhancement in current density $(2.262 \times$ $\left.10^{-4} \mathrm{~A}\right)$ as compared to NSPANI $\left(8.181 \times 10^{-6} \mathrm{~A}\right)$ and NSPANI/GR $\left(4.47 \times 10^{-5} \mathrm{~A}\right)$ nanocomposite The value of the maximum peak current obtained as for NSPANI (curve a) increases to (curve c) on incorporation of graphene and gold into NSPANI. This suggests that conducting nature of graphene and gold results in increased charge transport in polyaniline. The peak current decreases with change in the concentration of graphene and gold from one particular concentration. This suggests the decreased ionic transport and electron transfer toward the NSPANI/AuNP/GR matrix. These results show the high

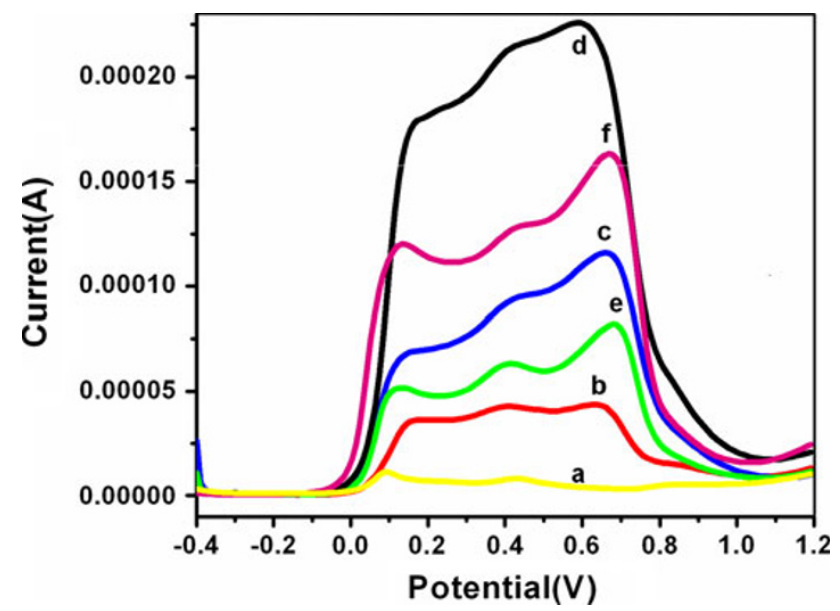

Fig. 3 Differential pulse voltammetry curves recorded for $a$ NSPANI, $b$ NSPANI/GR, $c$ NSPANI/AuNP/GR1, $d$ NSPANI/AuNP/GR, $e$ NSPANI/AuNP/GR2 and $f$ NSPANI/AuNP1/GR electron communication feature of the NSPANI/AuNP/GR nanocomposite. Thus, the optimum concentration of aniline:graphene:gold is 100:1:0.37.

\section{Conductivity measurements}

Conductivity is one of the most important properties of polymer nanocomposites for applications in devices. Conductivity of various nanocomposites is shown in Fig. 4. It is clear to see that conductivity strongly increases from $1.14 \times 10^{-5} \mathrm{~S} / \mathrm{cm}$ for NSPANI to $1.51 \times 10^{-5} \mathrm{~S} / \mathrm{cm}$ for NSPANI/GR and $4.31 \times 10^{-5} \mathrm{~S} / \mathrm{cm}$ for NSPANI/AuNP/ GR. This is because of two factors: one is that the gold nanoparticles serve as conductive bridges in the NSPANI/ GR matrix resulting in the improved charge transfer and demonstrating a synergy effect on the electrical properties of graphene and polyaniline; another is that there exists interaction between the gold nanoparticles and the NSPANI/GR. Based on these two factors, we have concluded that gold nanoparticles increases the conductivity of the polymer nanocomposite. It has been found that conductivity decreases if we change the concentration of graphene as well as gold nanoparticles from one particular concentration. It is quite possible that at a particular concentration, conductivity network is formed between NSPANI, graphene and gold nanoparticles, resulting in the strong increase in conductivity in the nanocomposite. This conductivity network is not formed if we change the concentration of graphene and gold nanoparticles.

Figure 5 represents the bar diagram of CV and DPV of various compositions of polymer nanocomposites. Maximum peak current is shown by NSPANI/AuNP/GR both in $\mathrm{CV}$ and DPV. From here we also come to the conclusion that the optimum concentration of aniline:graphene:gold is 100:1:0.37 for the synthesis of polyaniline nanocomposite.

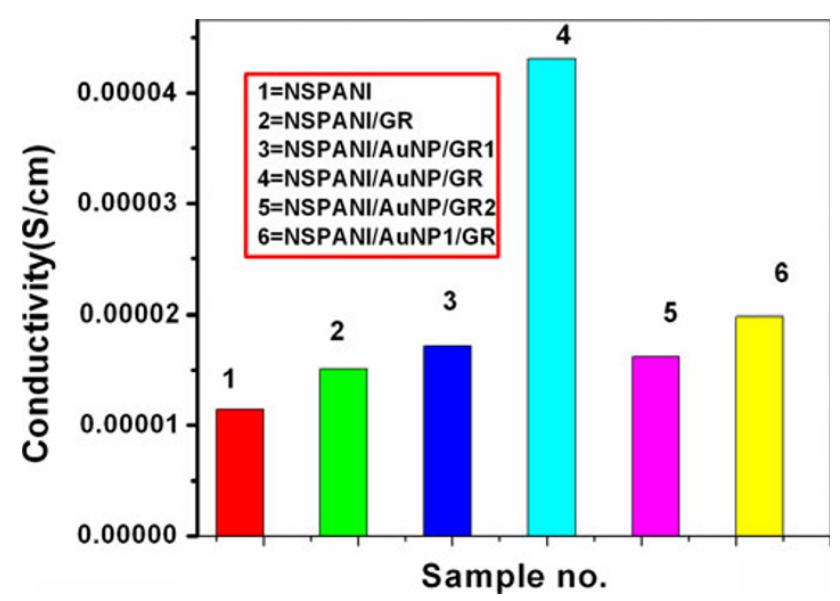

Fig. 4 Conductivity measurements for 1 NSPANI, 2 NSPANI/GR, 3 NSPANI/AuNP/GR1, 4 NSPANI/AuNP/GR, 5 NSPANI/AuNP/GR2 and 6 NSPANI/AuNP1/GR 


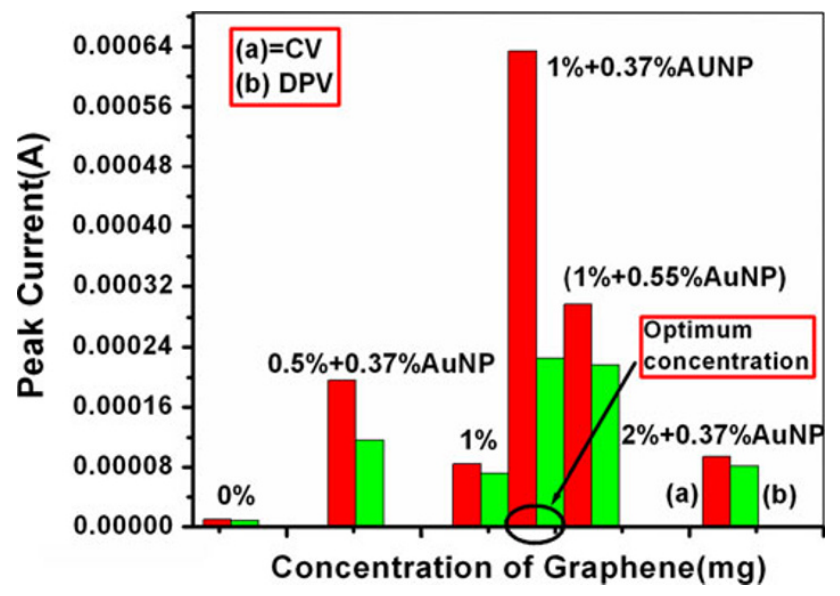

Fig. 5 Bar diagram of concentration of graphene $(\mathrm{mg})$ against peak current (A)

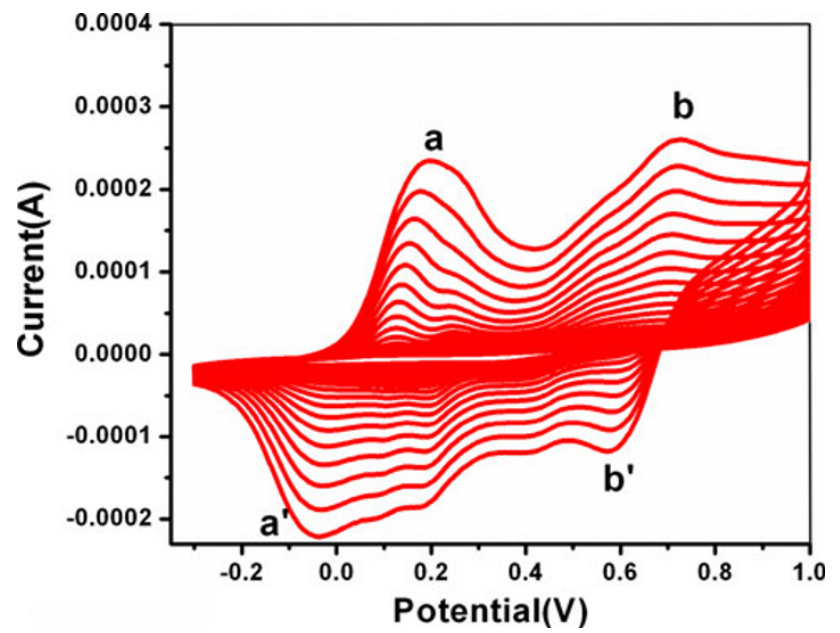

Fig. 6 Electrodeposition of NSPANI/AuNP/GR on the ITO Electrode

Thus, NSPANI/AuNP/GR is the best sample in terms of conductivity and electrochemical activity.

Film forming ability of the best sample (NSPANI/ AuNP/GR) on the ITO surface is also checked. The potential is swept from $-200 \mathrm{mV}$ to $+1,000 \mathrm{mV}$ (vs. $\mathrm{Ag} /$ $\mathrm{AgCl}$ ) at a scan rate of $80 \mathrm{mV} / \mathrm{s}$, in a three-electrodes cell consisting of $\mathrm{Ag} / \mathrm{AgCl}$ as reference, platinum $(\mathrm{Pt})$ as counter electrode and ITO as a working electrode. Figure 6 represents the electrodeposition of polymer nanocomposite on the ITO surface by CV method. The increase in current density with successive scans suggests that the polymer nanocomposite film build up on the electrode surface. This shows that NSPANI/AuNP/GR also gives optimum results with respect to film forming property.

We have chosen now NSPANI/AuNP/GR as a best sample and further studied its structure and morphology by
FT-IR Raman, XRD, SEM, TEM and AFM to confirm its synthesis.

\section{Raman spectra}

Figure 7 shows the Raman spectroscopy of NSPANI, NSPANI/GR and NSPANI/AuNP/GR composites. A broad $D$ band and $G$ band were observed in the Raman spectrum. In the Raman spectrum, the $\mathrm{G}$ band represents the in-plane bond-stretching motion of the pairs of $\mathrm{C} \mathrm{sp}^{2}$ atoms (the E2g phonons); while the $\mathrm{D}$ band corresponds to breathing modes of rings or K-point phonons of $\mathrm{A} 1 \mathrm{~g}$ symmetry (Ferrari and Robertson 2000; Cancado et al. 2004). For NSPANI/GR composite, $\mathrm{C}-\mathrm{H}$ bending of quinoid ring at $1,164 \mathrm{~cm}^{-1}, \mathrm{C}-\mathrm{N}^{+}$stretching at $1,344 \mathrm{~cm}^{-1}$ and $\mathrm{C} \equiv \mathrm{N}$ stretching vibration at $1,452 \mathrm{~cm}^{-1}$ are observed, revealing the presence of the polyaniline structures (Cochet et al. 2000). Compared with NSPANI, the NSPANI/GR composite presents a shift of the $\mathrm{C}-\mathrm{N}^{+}$stretching peak toward low wavenumbers resulting from the $\pi-\pi^{*}$ electron interaction between GR and aniline monomer. When compared to the spectrum of NSPANI/AuNP/GR, the Raman G band slightly shifts from 1,588 to $1,592 \mathrm{~cm}^{-1}$ due to the p-doping effects imposed by the AuNP nanoparticles (Dong et al. 2009). Consistent with AFM, TEM and SEM imaging, these results show that Au nanoparticles are tightly attached to the surface of NSAPNI/GR sheets and are uniformly distributed.

X-ray diffraction (XRD) studies

Figure 8 shows the XRD patterns of (a) NSPANI, (b) NSPANI/GR, (c) NSPANI/AuNP/GR nanocomposite.

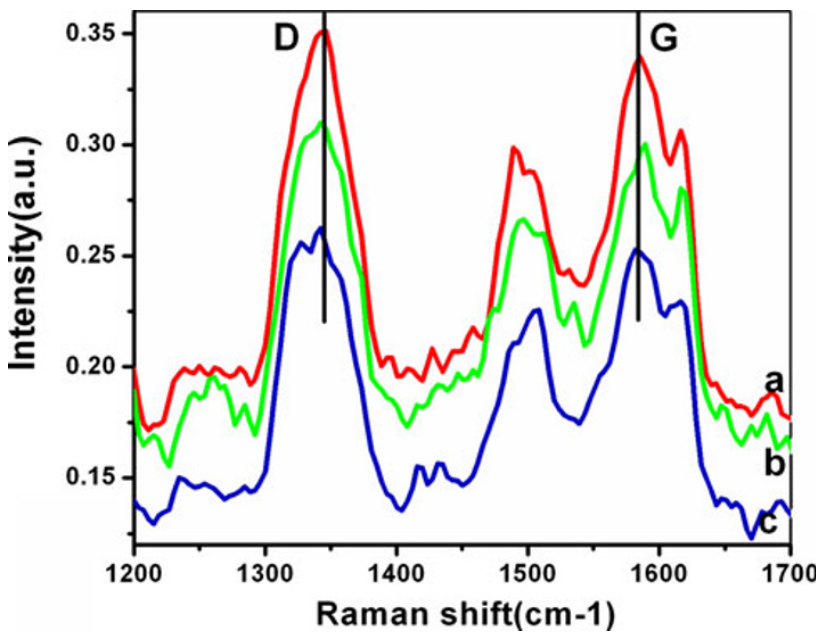

Fig. 7 Raman spectroscopy of $a$ NSPANI, $b$ NSPANI/GR and c NSPANI/AuNP/GR nanocomposite 


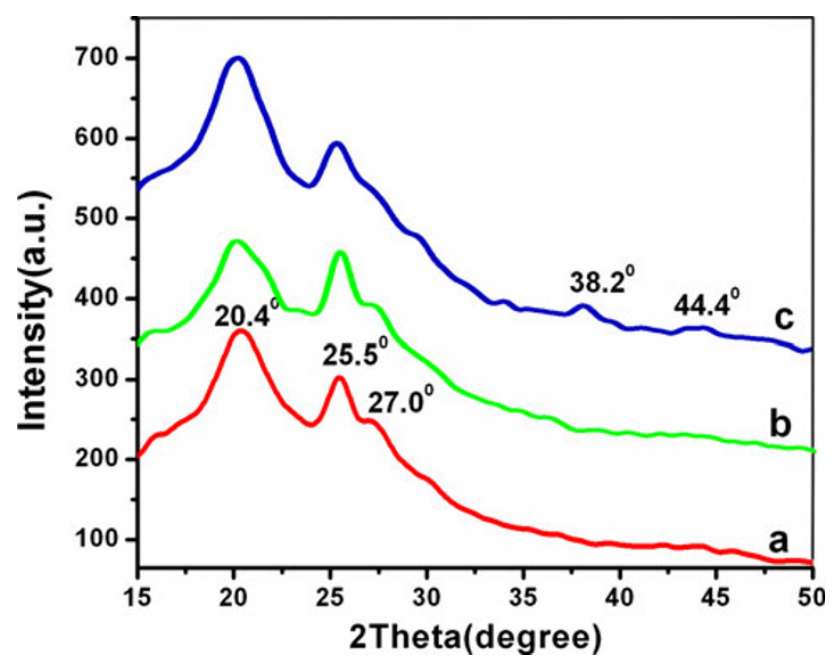

Fig. 8 XRD patterns of $a$ NSPANI, $b$ NSPANI/GR and $c$ NSPANI/ AuNP/GR nanocomposite

For NSPANI, the crystalline peaks appear at $2 \theta=20.4^{\circ}$, $25.5^{\circ}$ and $27.0^{\circ}$, corresponding to $\left(\begin{array}{lll}0 & 1 & 1\end{array}\right),\left(\begin{array}{lll}0 & 2 & 0\end{array}\right)$ and $\left(\begin{array}{ll}2 & 0\end{array}\right.$ 0 ) crystal planes of polyaniline in its emeraldine salt form, respectively (Chaudhari and Kelkar 1997). The X-ray data of NSPANI/GR composite presents crystalline peaks similar to those obtained from pure NSPANI, revealing that no additional crystalline order has been introduced into the composite and indicating that GR nanosheets are fully interacted with NSPANI and completely covered by polyaniline nanoparticles. Furthermore, as shown in Fig. 8 (line c), there are two new peaks for the NSPANI/AuNP/ GR hybrid material located at $38.2^{\circ}$ and $44.4^{\circ}$ which can be assigned to (1 111$)$ and (2 000$)$ faces of the gold nanoparticles on the surface of NSPANI/GR. The size of nanoparticles can be determined by XRD by applying Debye-Scherrer's formula as follows:

$D=0.9 \lambda / \mathrm{w} \cos \theta$

where $D$ is the size of nanoparticle, $\lambda$ is the wavelength used for XRD, $w$ is the full width half maxima and $\theta$ is the peak position

By applying this formula, we have calculated the size of nanoparticles as $70 \mathrm{~nm}$.

Scanning electron microscopy

Scanning electron microscopy (SEM) was utilized to analyze the morphology of the NSPANI, NSPANI/GR and NSPANI/AuNP/GR nanocomposites. It is clear that in NSPANI (Fig. 9a), a tube-like morphology was formed in the form of a network, with diameters from 20 to $50 \mathrm{~nm}$. In the polymer nanocomposite (Fig. 9b), the tube-like morphology of the neat NSPANI is less visible as NSPANI is attached onto the surface of graphene. It is well known that, when $\mathrm{HCl}$ is used as a dopant, the aniline monomer was absorbed onto the surface of GR through electrostatic attraction by the formation of weak charge-transfer complexes between aniline monomer and the graphitic structure of graphene. As a result of the absorption process, GR were coated by NSPANI particles by in situ polymerization of aniline monomer in the presence of graphene. Figure 9c shows the SEM image of the NSPANI/AuNP/GR nanocomposite. It is clear that gold nanoparticles are homogeneously distributed on the surface of the NSPANI/GR. Graphene is used as support material for deposition of NSPANI particles and gold nanoparticles as conductive wires interconnected among NSPANI/GR, such structure would be beneficial to further improve the conductivity of the composite.

Transmission electron microscopy (TEM)

Figure 10 represents the transmission electron microscopy of the NSPANI, NSPANI/GR and NSPANI/AuNP/GR. Very uniform spherical nanoparticles (Fig. 10a) have been obtained with NSPANI. During polymerization with graphene and gold, the NSPANI homogeneously coat on the surfaces of GR nanosheet (Fig. 10b). Polyaniline nanoparticles preferentially grow on the surfaces of GR due to their high chemical activity and surface area (Paek et al. 2009). In case of NSPANI/AuNP/GR nanocomposite (Fig. 10c), it can be seen that gold nanoparticles are well dispersed in NSPANI/GR matrix, which facilitate the yield of the conductive bridge within the NSPANI/GR matrix. The conductive bridge was believed to lead to the greatly improved electrical conductivity of the polyaniline composites (Chen et al. 2003; Mo et al. 2007).

\section{Atomic force microscopy}

Atomic force microscopy (AFM) is employed to establish the thickness, surface morphology and surface roughness of the NSPANI, NSPANI/GR and NSPANI/AuNP/GR depositions. The surface is characterized by a uniform array of nanoparticulate NSPANI nodules. The images (Fig. 11) indicate homogeneous and continuous films. Roughness parameters are compared for all the three depositions in Table 3.

Out of all the depositions, only NSPANI/AuNP/GR film has minimum root mean square roughness, average roughness and ten point average roughness. This shows that NSPANI/AuNP/GR film is homogenous and continuous and it can be further used for any device application. 

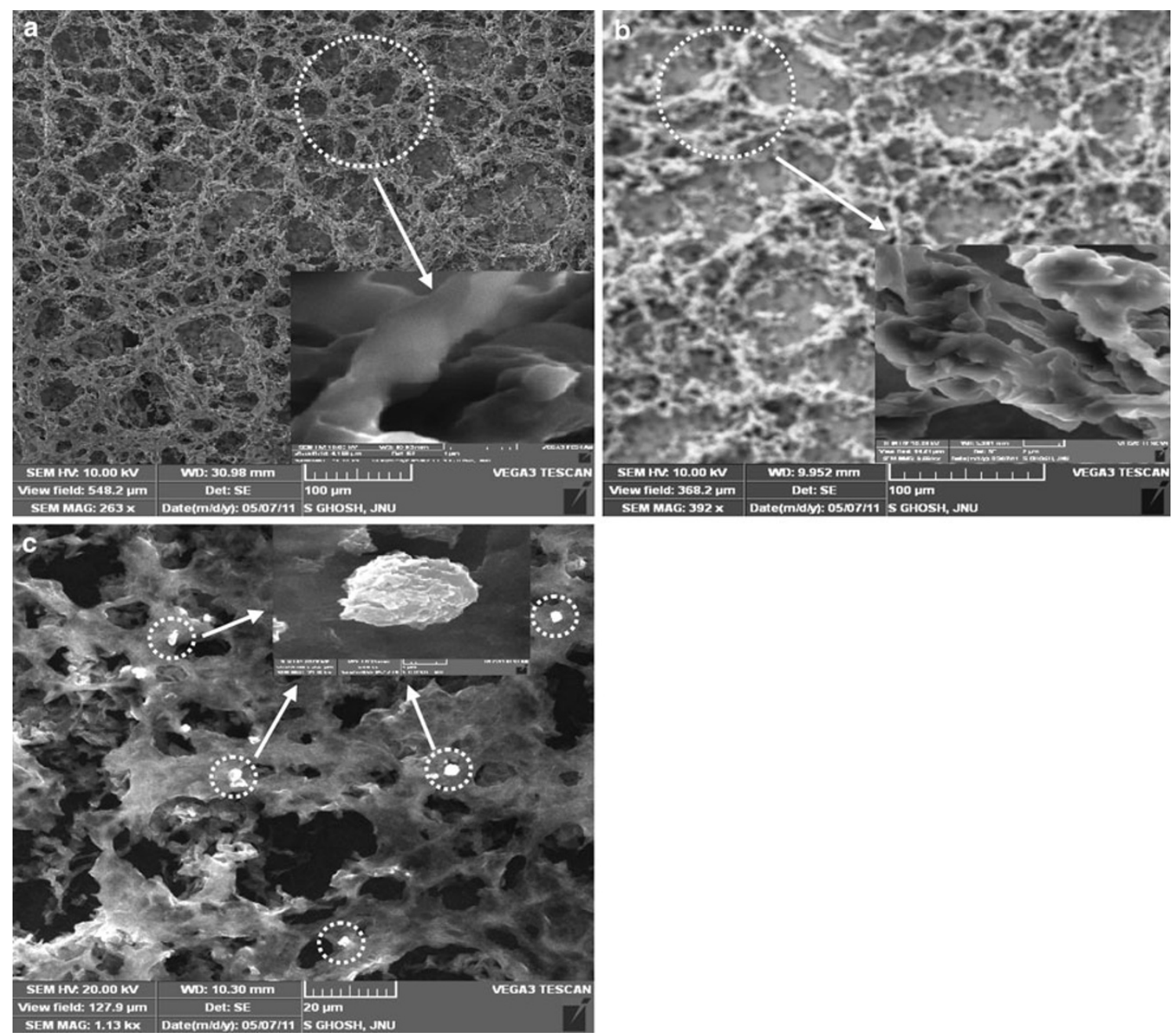

Fig. 9 SEM images of a NSPANI, b NSPANI/GR and c NSPANI/AuNP/GR (under low magnification). Inset shows high magnification

\section{Comparison of electrochemical activity of NSPANI/ AuNP/GR nanocomposite formed by in situ polymerization and blending process}

In order to understand the mechanism of formation and structure of NSPANI/AuNP/GR, we have synthesized the same composition of NSPANI/AuNP/GR nanocomposite by blending process. In the blending process, time for the addition of gold has been varied by keeping the concentration of NSPANI and graphene constant (Table 2) and total time for stirring is $2 \mathrm{~h}$. The $\mathrm{CV}$ of all the blending samples has been taken (Fig. 12a). It has been found that $\mathrm{CV}$ wave current increases from sample 1 to sample 3 but afterwards the wave current decreases for sample 4 . This is due to the insufficient time available for the binding of gold nanoparticles on the surface of NSPANI/GR nanosheets. The NSPANI/AuNP/GR nanocomposite synthesized by both methods is also tested for electrochemical stability (Fig. 12a). The CV wave current of composite formed by blending process is decreased as compared to that formed by in situ polymerization. This is mainly due to phase separation due to the release of individual entities from the nanocomposite formed by blending process. Whereas there are strong physio-chemical interactions prevailing between the various constituents in the nanocomposite formed by in situ polymerization. Similar results are obtained with Differential pulse voltammetry (Fig. 12b). Maximum current $\left(2.262 \times 10^{-4} \mathrm{~A}\right)$ is obtained for NSPANI/AuNP/GR nanocomposite formed by in situ polymerization as compared to other samples formed by blending process. On the basis of the electrochemical results explained above, it can be concluded that the NSPANI/AuNP/GR formed by in situ polymerization has the best maximum electrochemical activity. 

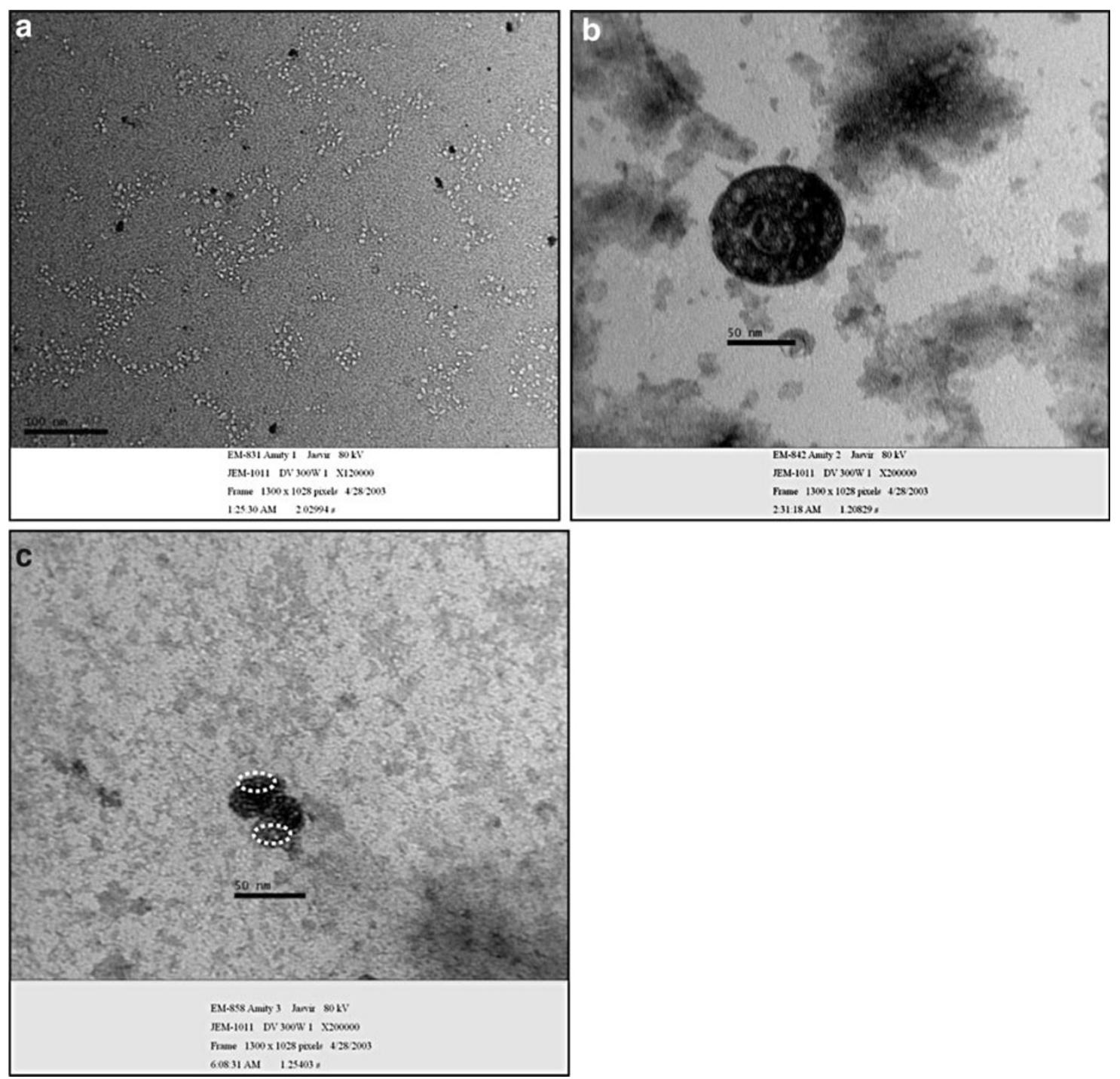

Fig. 10 TEM images of a NSPANI, b NSPANI/GR and $\mathbf{c}$ NSPANI/AuNP/GR

\section{Mechanism of formation}

From the above study, a mechanism has been proposed for in situ formation of NSPANI/AuNP/GR nanocomposite. The formation mechanism of NSPANI/AuNP/GR nanocomposite is depicted in Scheme 2. The graphene nanosheet being electron acceptor and aniline being electron donor form a kind of weak charge-transfer complex (Sun et al. 2001). When aniline monomers are added into the graphene suspension, aniline monomers can immediately absorb onto the surfaces of graphene nanosheet due to the electrostatic attraction. Graphene as a support material could supply a large number of active sites for nucleation of polyaniline and further the gold nanoparticles coat on the surface of polyaniline due to the strong physio-chemical interactions. Gold nanoparticles act as conductive wires between polyaniline and graphene which can be attributed to a synergistic effect stemming from the presence of gold nanoparticles between graphene and polyaniline which may be favorable for the enhancement of the electrochemical performance as an electrode for biosensors.

\section{Conductivity theory}

Highest conductivity is obtained for NSPANI/AuNP/Gr nanocomposite $\left(4.31 \times 10^{-5}\right)$ as is revealed from conductivity measurements (Fig. 4). This data reveal that the polyaniline in the composites is richer in quinoid units than the NSPANI. This also suggests that the chains of the polyaniline deposited on the surface of the graphene have longer conjugation lengths. The $\pi$-bonded surface of the graphene might interact strongly with the conjugated 

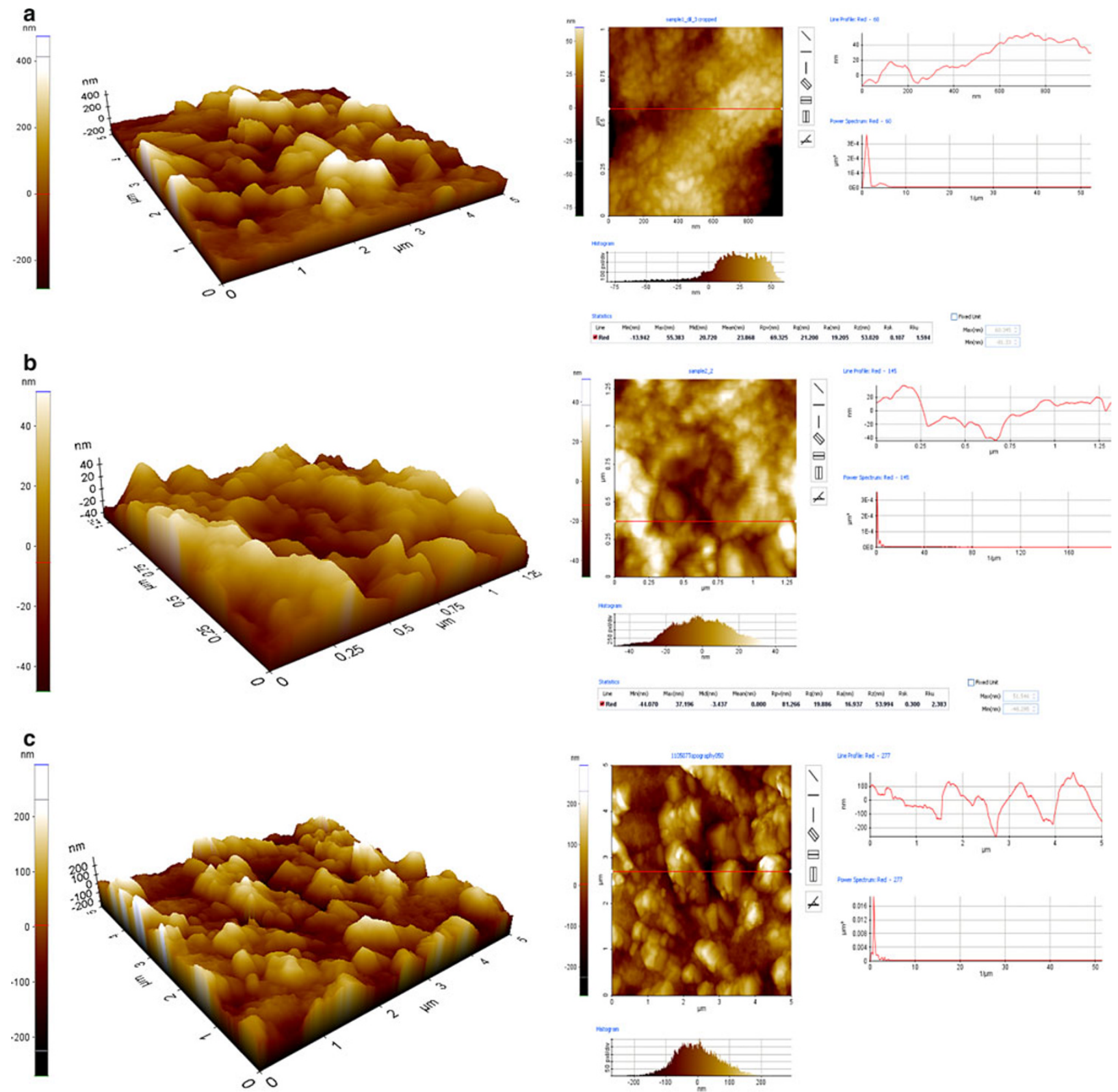

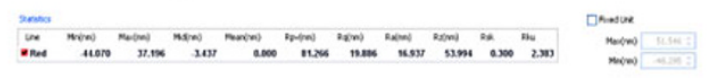
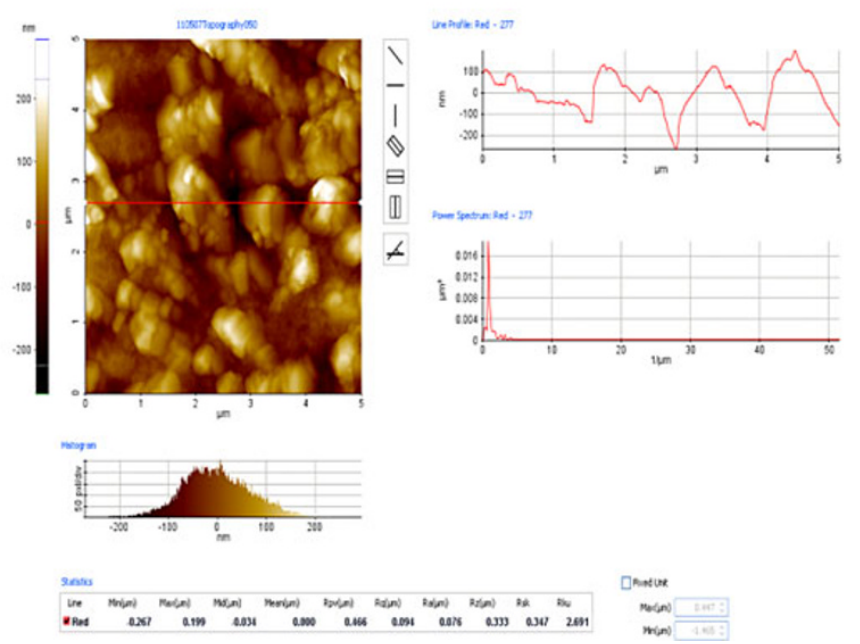

Fig. 11 AFM images of a NSPANI, b NSPANI/GR and c NSPANI/AuNP/GR

Table 3 Roughness parameters for the nanocomposites

\begin{tabular}{lllc}
\hline Sample name & $\begin{array}{l}\text { Root mean square } \\
\text { roughness } R_{\mathrm{q}}(\mathrm{nm})\end{array}$ & $\begin{array}{l}\text { Average roughness } \\
R_{\mathrm{a}}(\mathrm{nm})\end{array}$ & $\begin{array}{l}\text { Ten point average } \\
\text { roughness } R_{\mathrm{z}}(\mathrm{nm})\end{array}$ \\
\hline NSPANI/AuNP/GR nanocomposite & 0.09 & 0.07 & 0.33 \\
NSPANI/GR nanocomposite & 19.8 & 16.9 & 53.9 \\
NSPANI nanodispersion & 21.2 & 19.2 & 53.0 \\
\hline
\end{tabular}




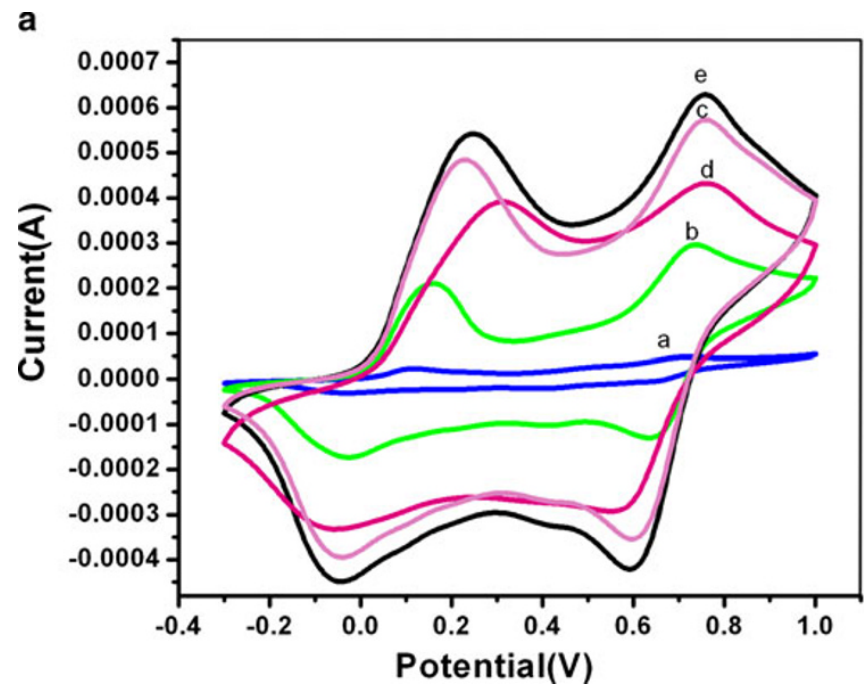

Fig. 12 a Cyclic voltammograms of $a$ blending sample 1, $b$ blending sample 2, $c$ blending sample 3, $d$ blending sample 4, $e$ in situ sample NSPANI/AuNP/GR. b Differential pulse voltammetry curves

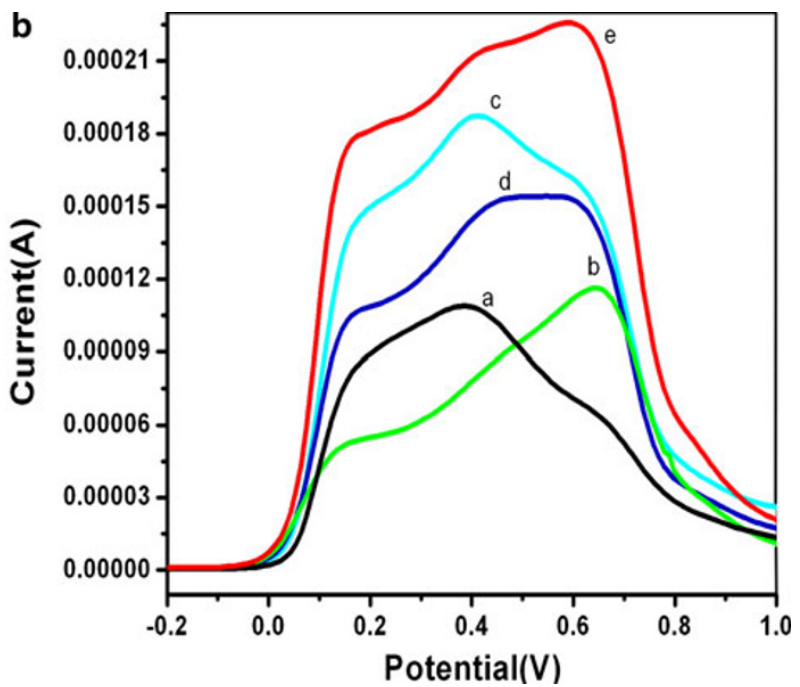

recorded for $a$ blending sample $1, b$ blending sample 2, $c$ blending sample 3, $d$ blending sample 4 and $e$ in situ sample NSPANI/AuNP/ GR

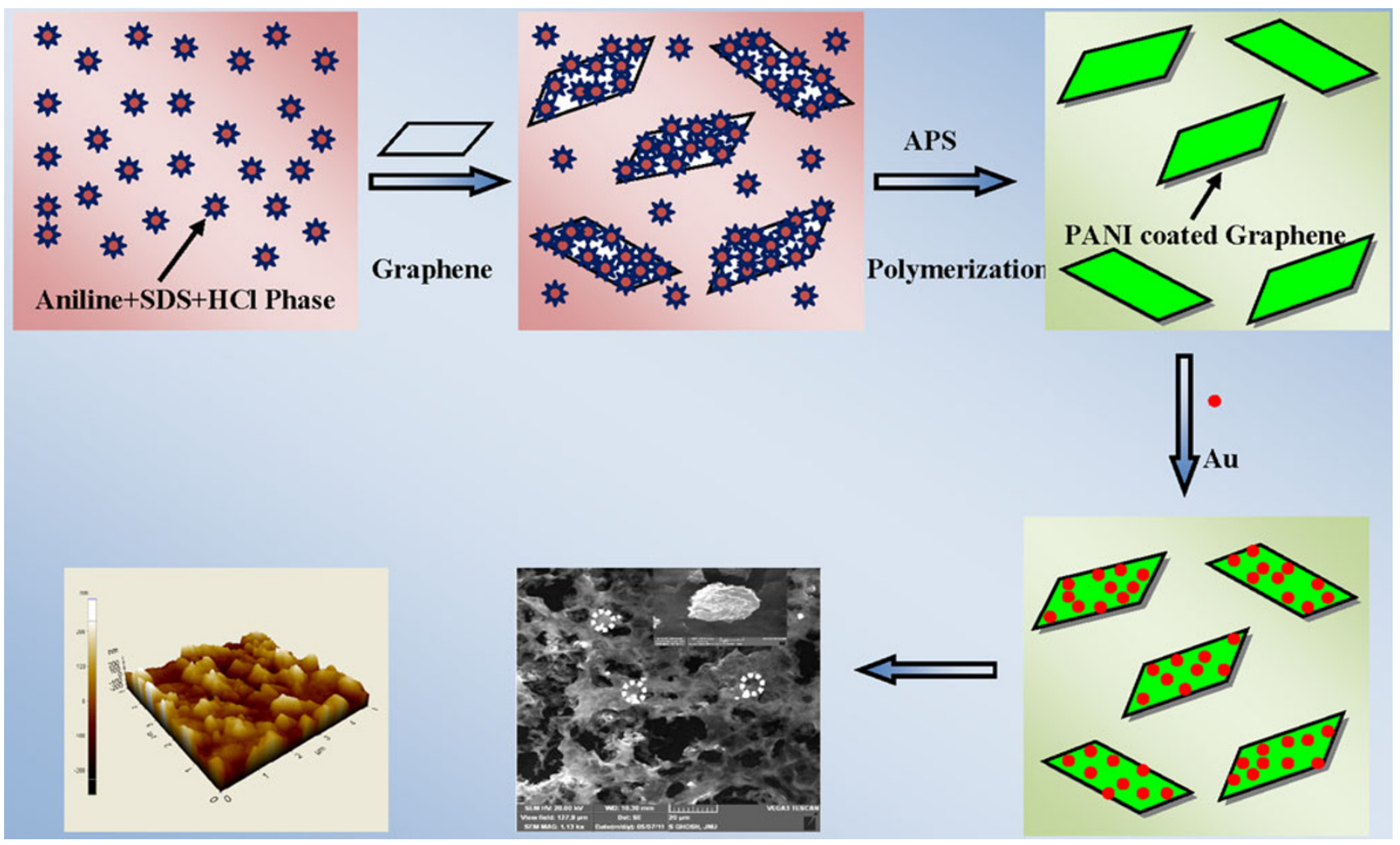

Scheme 2 Schematic diagram for the synthesis of NSPANI/AuNP/GR composite

structure of polyaniline, especially via the quinoid ring (Quillard et al. 1994). In general, aromatic structures are known to interact strongly with the basal plane of the graphitic surface via $\pi$-stacking (Park et al. 2009). The interaction between the quinoid ring of the polyaniline and the graphene may facilitate the charge-transfer process between the components of the system and increase the effective degree of electron delocalization, thereby enhancing the conductivity of the composites (Park et al. 2009). It is expected that Au nanoparticles doped onto 
polyaniline lead to the bridge effect between graphene and polyaniline, resulting in the improved charge transfer and demonstrating a synergy effect on the electrical properties. This indicates that gold nanoparticles and graphene can serve as effective conducting fillers to enhance the electrical properties of polyaniline (Ma et al. 2008).

\section{Conclusions}

Polymer nanocomposites (NSPANI/AuNP/GR) based on nanostructured polyaniline, gold nanoparticles (AuNP) and graphene nanosheets (GR) have been synthesized using in situ polymerization. A series of nanocomposites have been synthesized by varying the concentration of graphene and chloroauric acid to optimize the formulation with respect to the electrochemical activities. Out of these series of NSPANI/AuNP/GR nanocomposites, it has been found that only one particular nanocomposite has the best electrochemical properties, as analyzed by cyclic voltammetry (CV) and differential pulse voltammetric (DPV) techniques and conductivity. The $\mathrm{CV}$ of the best nanocomposites show the well-defined reversible redox peaks characteristic of polyaniline, confirming that the polymer maintains its electro activity in the nanocomposites. Furthermore, the best NSPANI/AuNP/GR has shown remarkable enhancement in current density $\left(6.22 \times 10^{-4} \mathrm{~A}\right)$ as compared to NSPANI $\left(9.58 \times 10^{-6} \mathrm{~A}\right)$ and NSPANI/GR $(4.54 \times$ $\left.10^{-5} \mathrm{~A}\right)$ nanocomposite indicating an optimum composite formulation. Another NSPANI nanocomposite has been prepared with identical composition (as found with the best nanocomposite) by mixing of pre-synthesized nanostructured polyaniline with chloroauric acid and graphene dispersion in order to predict the mechanism of in situ formation of nanocomposite. The electrochemical properties of both the nanocomposites has been compared and shown that the nanocomposite prepared by blending technique loses its property within $48 \mathrm{~h}$ indicating phase separation whereas the nanocomposite prepared by in situ technique is highly stable. These intriguing features of the nanocomposites make them promising materials for applications in biosensors.

Acknowledgments We acknowledge the financial assistance received from the Department of Biotechnology, Govt. of India (Project No BTPR 11123/MD/32/41/2008 DBT). We are thankful to Dr. A. K. Chauhan (Founder President, Amity University, Uttar Pradesh) for providing the platform for research at Amity University Uttar Pradesh and we also offer our sincere thanks to Dr.(Mrs.) Balwinder Shukla, Director General A.S.E.T, Dr. R. P. Singh, Director, AINT and Prof. A. K. Srivastava, Director General, AIB, AUUP for their constant support and encouragement. We are also thankful to Dr. Subhasish Ghosh, Akansha and Pawan, JNU New Delhi for conducting SEM and AFM studies.
Open Access This article is distributed under the terms of the Creative Commons Attribution License which permits any use, distribution, and reproduction in any medium, provided the original author(s) and the source are credited.

\section{References}

Bai H, Xu Y, Zhao L, Li C, Shi G (2009) Non-covalent functionalization of graphene sheets by sulfonated polyaniline. Chem Commun 46:1667-1669

Banerjee P, Mandal BM (1995) Blends of HCl-doped polyaniline nanoparticles and poly (vinyl chloride) with extremely low percolation threshold—a morphology study. Synth Met 74:257

Bianchi RF, Ferreira GFL, Lepienski CM, Faria RM (1999) Alternating electrical conductivity of polyaniline. J Chem Phys 110:4602

Bourdo S, Li Z, Biris AS, Watanabe F, Viswanathan T, Pavel I (2008) Structural, electrical, and thermal behavior of graphite-polyaniline composites with increased crystallinity. Adv Funct Mater 18:432-440

Cancado LG, Pimenta MA, Neves BRA, Dantas MSS, Jorio A (2004) Influence of the atomic structure on the Raman spectra of graphite edges. Phys Rev Lett 93:247401

Chaudhari HK, Kelkar DS (1997) Investigation of structure and electrical conductivity in doped polyaniline. Polym Int 42:380-384

Chen GH, Weng WG, Wu DJ (2003) PMMA/graphite nanosheets composite and its conducting properties. Eur Polym J 39:2329-2335

Cochet M, Louarn G, Quillard S, Buisson JP, Lefrant S (2000) Theoretical and experimental vibrational study of emeraldine in salt form. Part II. J Raman Spectrosc 31:1041-1049

Dong XC, Fu DL, Fang WJ, Shi YM, Chen P, Li LJ (2009) Doping single-layer graphene with aromatic molecules. Small 5:1422

Dong X, Shi Y, Huang W, Chen P, Li LJ (2010) Electrical detection of DNA hybridization with single-base specificity using transistors based on CVD-grown graphene sheets. Adv Mater 22:1649-1653

Ferrari AC, Robertson J (2000) Interpretation of Raman spectra of disordered and amorphous carbon. Phys Rev B 61:14095-14107

Geim AK (2009) Graphene: status and prospects. Science 324:15301534

Goswami S, Maiti UN, Maiti S, Nandy S, Mitra MK, Chattopadhyay KK (2011) Preparation of graphene-polyaniline composites by simple chemical procedure and its improved field emission properties. Carbon 49:2245-2252

Holdcroft S (2008) Bilayer approach to laser-induced thermal patterning of $\pi$-conjugated polymers. Adv Mater 20:2486-2490

Hong W, Bai H, Xu Y, Yao Z, Gu Z, Shi G (2010) Preparation of gold nanoparticle/graphene composites with controlled weight contents and their application in biosensors. J Phys Chem C 114:1822-1826

Hongkun HE, Chao G (2011) Graphene nanosheets decorated with $\mathrm{Pd}, \mathrm{Pt}, \mathrm{Au}$, and $\mathrm{Ag}$ nanoparticles: synthesis, characterization, and catalysis applications. Sci China Chem 54:397-404

Huang WS, Humphrey BD, MacDiarmid AG (1986) Polyaniline, a novel conducting polymer: morphology and chemistry of its oxidation and reduction in aqueous electrolytes. $\mathrm{J}$ Chem Soc 82:2385-2400

Huang J, Virji S, Weiller BH, Kaner RB (2004) Nanostructured polyaniline sensors. Chem Eur J 10:1314

Janata J, Josowicz M (2003) Conducting polymers in electronic chemical sensors. Nat Mater 2:19-24 
Kim KS, Kim IJ, Park SJ (2010) Influence of Ag doped graphene on electrochemical behaviors and specific capacitance of polypyrrole-based nanocomposites. Synth Met 160:2355-2360

Li X, Zhao Y, Zhuang T, Wang G, Gu O (2007) Synthesis of polyaniline nanofibrils using an in situ seeding technique. Colloid Surf A 295:146

Li D, Müller MB, Gilje S, Kaner RB, Wallace GG (2008) Processable aqueous dispersions of graphene nanosheets. Nat Nanotechnol 3:101-105

Liu J, Tian S, Knoll W (2005) Properties of polyaniline/carbon nanotube multilayer films in neutral solution and their application for stable low-potential detection of reduced beta-nicotinamide adenine dinucleotide. Langmuir 2:5596-5599

Liu Z, Robinson JT, Sun X, Dai H (2008) PEGylated nanographene oxide for delivery of water-insoluble cancer drugs. J Am Chem Soc 130:10876-10877

Lu CH, Zhu CL, Li J, Liu JJ, Chen X, Yang HH (2010) Using graphene to protect DNA from cleavage during cellular delivery. Chem Commun 46:3116-3118

Ma PC, Tang BZ, Kim JK (2008) Effect of CNT decoration with silver on electrical conductivity of CNT-polymer composites. Carbon 46:1497

MacDiarmid AG (1997) Application of electroactive polymers. Synth Met 84:27-34

MacDiarmid AG, Chiang JC, Halpern M, Huang WS, Mu SL, Somasiri NLD, Wu WQ, Yaniger SI (1985) Polyaniline: interconversion of metallic and insulating forms. Mol Cryst Liq Cryst 121:173-180

Mo ZL, Zuo DD, Chen H (2007) Synthesis of graphite nanosheets/ $\mathrm{AgCl} /$ polypyrrole composites via two-step inverse microemulsion method. Eur Polym J 43:300-306

Murugan AV, Muraliganth T, Manthiram A (2009) Microwavesolvothermal synthesis of graphene nanosheets and their polyaniline nanocomposites for energy storage. Chem Mater 21:5004

Nandi MA, Gangopadhyay RB, Bhaumik A (2007) Mesoporous polyaniline having high conductivity at room temperature. Microporous Mesoporous Mater 109:239-247

Paek SM, Yoo E, Honma I (2009) To fabricate nanoporous electrode materials with delaminated structure, the graphene nanosheets (GNS). Nano Lett 9:72

Park OK, Jeevananda T, Kim NH, Kim S, Lee JH (2009) Effects of surface modification on the dispersion and electrical conductivity of carbon nanotube/polyaniline composites. Scripta Mater 60:551-554

Quillard S, Louarn G, Lefrant S, MacDiarmid AG (1994) Vibrational analysis of polyaniline. A comparative study of leucoemeraldine, emeraldine, and pernigraniline bases. Phys Rev B 50:12496

Shen J, Shi M, Li N, Yan B, Ma H, Hu Y, Ye M (2010) Facile synthesis and application of Ag-chemically converted graphene nanocomposite. Nano Res 3:339-349

Stejskal J, Kratochvil P (1993) Polyaniline dispersions-UV-vis absorption spectra. Synth Met 61:225-231

Stoller MD, Park SJ, Zhu YW, An J, Ruoff RS (2008) Graphenebased ultracapacitors. Nano Lett 8:3498
Sun Y, Wilson SR, Schuster DI (2001) High dissolution and strong light emission of carbon nanotubes in aromatic amine solvents. J Am Chem Soc 123:5348-5349

Tang LAL, Wang J, Loh KP (2010) Graphene-based SELDI probe with ultrahigh extraction and sensitivity for DNA oligomer. J Am Chem Soc 132:10976-10977

Thanpitcha T, Sirivat A, Jamieson AM, Rujiravanit R (2008) Synthesis of polyaniline nanofibrils using an in situ seeding technique. Synth Met 158:695-703

Virji S, Huang J, Kaner RB, Weiller BH (2004) Polyaniline nanofiber gas sensors: examination of response mechanism. Nano Lett 4:491-496

Wang J, Chan S, Carlson RR, Luo Y, Ge GL, Ries RS, Heath JR, Tseng HR (2004) Electrochemically fabricated polyaniline nanoframework electrode junctions that function as resistive sensors. Nano Lett 4:1693-1697

Wang YG, Li HQ, Xia YY (2006) Ordered whiskerlike polyaniline grown on the surface of mesoporous carbon and its electrochemical capacitance performance. Adv Mater 18:2619

Wang CY, Mottaghitala V, Too CO, Spinks GM, Wallace GG (2007) Polyaniline and polyaniline-carbon nanotube composite fibres as battery materials in ionic liquid electrolyte. J Power Sources 163:1105

Wang DW, Li F, Zhao JP, Ren WC, Chen ZG, Tan J, Wu ZS, Gentle L, Lu GQ, Chen HM (2009a) Enhanced electrochemical sensitivity of $\mathrm{PtRh}$ electrodes coated with nitrogen-doped graphene. ACS Nano 3:1745

Wang H, Hao Q, Yang X, Lu L, Wang X (2009b) External link Graphene oxide doped polyaniline for supercapacitors. Electrochem Commun 11:1158

Wang H, Hao Q, Yang X, Lu L, Wang X (2010) A nanostructured graphene/polyaniline hybrid material for supercapacitors. Nanoscale 2:2164-2170

Wu Q, Xu Y, Yao ZY, Liu A, Shi GQ (2010) Supercapacitors based on flexible graphene/polyaniline nanofiber composite films. ACS Nano 4:1963-1970

Xia L, Wei Z, Wan M (2010) Conducting polymer nanostructures and their application in biosensors. J Colloid Interface Sci 341:1-11

Yang N, Zhai J, Wan M, Wang D, Jiang L (2010) Layered nanostructures of polyaniline with graphene oxide as the dopant and template. Synth Met 160:1617-1622

Zhang K, Zhang LL, Zhao XS, Wu J (2010) Graphene/Polyaniline nanofiber composites as supercapacitor electrodes. Chem Mater 22:1392-1401

Zhang Z, Chen H, Xing C, Guo M, Xu F, Wang X, Gruber HJ, Zhang B, Tang J (2011) Sodium citrate: a universal reducing agent for reduction/decoration of graphene oxide with $\mathrm{Au}$. Nano Res 4:599-611

Zhou X, Wu T, Hu B, Yang G, Han B (2010) Synthesis of graphene/ polyaniline composite nanosheets mediated by polymerized ionic liquid. Chem Commun 46:3663 